\title{
A INFLUÊNCIA DA MUDANÇA NA CULTURA E NO CLIMA ORGANIZACIONAL: O CASO DO INSTITUTO FEDERAL DA PARAÍbA (IFPB), CAMPUS SOUSA
}

\section{THE INFLUENCE OF CHANGE IN CULTURE AND ORGANIZATIONAL CLIMATE: THE CASE OF THE FEDERAL INSTITUTE OF PARAÍBA (IFPB), CAMPUS SOUSA}

\author{
Joselma Mendes de Sousa Carneiro $^{1}$ \\ Wilson Honorato Aragão ${ }^{2}$ \\ Maria das Graças Gonçalves Vieira Guerra ${ }^{3}$
}

\section{Resumo}

Este trabalho trata da mudança implantada pela Lei $n^{\circ} 11.892 / 2008$ que integrou as Escolas Técnicas, Agrotécnicas e Centros Federais de Educação para a formação dos Institutos Federais de Educação no Brasil. Na Paraíba, a Escola Agrotécnica Federal de Sousa passou a ser o Instituto Federal da Paraíba (IFPB), Campus Sousa foi objeto desta pesquisa. O objetivo foi analisar a influência da mudança sobre a cultura e o clima organizacional do IFPB, Campus. A metodologia utilizada foi o estudo de caso e a estratégia qualitativa com utilização da entrevista e do questionário. Portanto, a mudança influenciou na cultura organizacional e no clima organizacional, modificando crenças, rituais, valores e que, apesar de estar em um estágio avançado, a organização ainda não tem uma identidade real definida, necessitando que haja um processo mais efetivo de socialização da identidade formal para que isto ocorra.

Palavras-chaves: Organização pública. Cultura Organizacional. Clima. Mudança. Identidade.

\footnotetext{
1 ) Mestre em Gestão nas organizações Aprendentes - MPGOA- UFPB e Chefe do Dept. Educação Superior do Instituto Federal da Paraíba- Campus Sousa. E-mail: joselmacarneiro2008@ hotmail.com

${ }^{2}$ Graduado em Licenciatura Plena em Educação Física pela Universidade Federal da Paraíba (1980), Mestrado em Educação pela Universidade Federal da Paraíba (1994) e Doutorado em Educação pela Universidade Federal do Rio Grande do Norte (2002). Atualmente é professor Associado II da Universidade Federal da Paraíba e Diretor do Centro de Educação/UFPB (2013-2016). Líder do grupo de pesquisa Exclusão, Inclusão e Diversidade. Tem experiência na área de Educação, com ênfase em Políticas Públicas, Politicas de Ações Afirmativas, Movimentos Sociais, atuando nos seguintes temas: Educação, Mercado de Trabalho, Política de Formação de Professores, Gestão Educacional, Educação a Distância, Educação Física e História e Cultura Afrobrasileira. E-mail: wilsonaragao@ hotmail.com

${ }^{3}$ Possui Doutorado em Educação (UFPB-2007), Mestrado em Administração (UFPB-2003), Especialização em EaD (UNIGRAN-EaD-2010), Bacharelado em Ciências Contábeis (UFPB-2000) e Licenciatura em Pedagogia (UNIGRAN-EaD-2012). Atualmente é Professora Associada I do Centro de Educação da Universidade Federal da Paraíba, Professora Pesquisadora I da Universidade Aberta do Brasil - UAB/UFPB, Coordenadora e Professora dos Programas de Pós-Graduação em Políticas Públicas, Gestão e Avaliação da Educação Superior da UFPB em Gestão nas Organizações Aprendentes da UFPB. Atualmente é a Representante dos Coordenadores do Centro de Educação na Comissão Própria de Avaliação - CPA da UFPB. Foi Professora da Universidade Federal de Pernambuco - UFPE (2009-2015). É Consultora ad doc - Avaliação de Cursos Superiores na Área de Ciências Contábeis, Administração e Pedagogia (SINAES/INEP/MEC). Líder do Grupo de Pesquisa GAES, que abarca investigações do campo na área de avaliação da educação superior, perpassado pelas políticas públicas, gestão e práticas educativas. Prestou Consultoria para a UNESCO/MEC, na área de Alfabetização e Educação de Jovens e Adultos (EJA). Tem experiência na área de Pedagogia, Educação a Distância, Avaliação do Ensino Superior, Administração e Contabilidade, atuando principalmente nos seguintes temas: avaliação do ensino superior, gestão, pedagogia e educação à distância. E-mail: gracinhavieira@ yahoo.com.br
}

Revista Labor Fortaleza/CE, jan/jul 2017 Vol.01, nº 18, p. 31-49 ISSN 1983-5000 


\begin{abstract}
This work deals with the change implemented by Law 11,892 / 2008 that integrated the Technical Schools, Agrotechnics and Federal Centers of Education for the formation of the Federal Institutes of Education in Brazil. In Paraíba, the Federal Agro-technical School of Sousa became the Federal Institute of Paraíba (IFPB), Campus Sousa was the object of this research. The objective was to analyze the influence of the change on the culture and the organizational climate of the IFPB, Campus. The methodology used was the case study and the qualitative strategy using the interview and the questionnaire. Therefore, the change has influenced the organizational culture and the organizational climate, modifying beliefs, rituals, values and that, despite being at an advanced stage, the organization does not yet have a definite real identity, necessitating a more effective process of socialization of the organization. Formal identity for this to occur.
\end{abstract}

Keywords: Public organization. Organizational culture. Climate. Change. Identity.

\title{
INTRODUÇÃO
}

Inicialmente, deve-se destacar que mudar exige decisão firme e objetivos claros, e quando a mudança surge no ambiente organizacional deve ainda, para obter sucesso, estar alicerçada nos valores, crenças e objetivos organizacionais para que não haja resistência ou retrocesso.

Em especial nas organizações públicas, verifica-se que as mudanças quase sempre são impostas por forças exteriores, restando às organizações buscar a adaptação da melhor forma possível, o que a princípio pode causar incerteza, resistência e outros sentimentos que podem ser a diferença entre o sucesso, ou não, das mudanças implantadas.

Sabe-se que a cultura organizacional instalada nas organizações sejam elas, públicas ou privadas, não é fácil de ser modificada, principalmente, quando não se conhece inteiramente as suas especificidades.

Nesse contexto, a mudança estrutural e cultural por que têm passado as Escolas Técnicas e Agrotécnicas Federais decorrente da criação dos Institutos Federais, instigou esse estudo. Em especial, por ser servidora de uma dessas escolas e ter vivenciado in loco essa mudança, desejando compreender até que ponto ela tem afetado a vida no Campus escolhido como local da pesquisa.

A Lei 11.892, publicada em 29/12/2008 foi considerada um marco no cenário educacional brasileiro por ser responsável pela criação, no âmbito do Ministério da Educação, de um novo modelo de gestão das Instituições de Ensino federais, recebendo a denominação de Instituto Federal de Educação, Ciência e Tecnologia, cujo objetivo foi gerar e fortalecer condições e estruturas necessárias ao desenvolvimento educacional e socioeconômico em Revista Labor Fortaleza/CE, jan/jul 2017 Vol.01, nº 18, p. 31-49 ISSN 1983-5000 
todas as regiões do país através da expansão do ensino médio, técnico e de capacitação, superior e de pós-graduação (PACHECO, 2011).

O novo modelo de gestão ${ }^{4}$ na forma de instituto foi estruturado a partir de um potencial instalado nos Centros Federais de Educação (CEFET’s), nas Escolas Técnicas e Escolas Agrotécnicas Federais, além de escolas vinculadas às Universidades Federais, e tem como um dos seus principais pilares, a inovação tecnológica.

Este artigo trata especificamente de analisar e descrever de modo geral como se deram os acontecimentos que embasaram a transformação das escolas Técnicas, Agrotécnicas e CEFETS em Institutos Federais e mais especificamente, como essa mudança foi recepcionada no estado da Paraíba pelo Instituto Federal da Paraíba, Campus Sousa.

\section{REFERENCIAL TEÓRICO}

Inicialmente, se deve salientar que os dois tipos de organizações, privada e pública, obedecem a sistemas e regras diversos quanto à forma de gestão administrativa e orçamentária, recrutamento, seleção, treinamento e permanência de pessoal em seus quadros de trabalhadores. Pode-se dizer que o conjunto desses diversos fatores determina, também, a denominada cultura organizacional.

Por outro lado, para se tornar estável, a organização deve criar e preservar uma identidade singular que a distinga no meio social, do qual sofre influências tanto do ambiente interno, a exemplo da entrada e saída de pessoas, alteração de metodologias de trabalho, introdução de novas tecnologias, como do ambiente externo, pois disto dependerá a preservação de sua essência, evitando sua extinção que, necessariamente se apresenta no seu modelo de gestão, o que nas organizações públicas não é muito diferente.

Hoje, como é sentido por todas as organizações, incluindo as públicas e em especial as educacionais, tem-se no capital humano, intelectual e do conhecimento seu maior bem, o que exige que deem prioridade ao gerenciamento do conhecimento e não apenas à administração de dados ou informações, interpretando corretamente as novas gerações que estão surgindo, a exemplo da geração Internet, que traz nova cultura, valores e perfil psicológico (TACHIZAWA, 2006).

Nesse contexto, a organização pública não está isolada, sofre influências dos diversos âmbitos e necessita estar a par das mudanças constantes, porém essa consciência não

\footnotetext{
${ }^{4}$ Conjunto de decisões exercidas, sob princípios de qualidade preestabelecidos com a finalidade de atingir e preservar um equilíbrio dinâmico entre objetivos, meios e atividades no âmbito das instituições de ensino. (TACHIZAWA; ANDRADE, 2006, p.59)

Revista Labor Fortaleza/CE, jan/jul 2017 Vol.01, nº 18, p. 31-49 ISSN 1983-5000
} 
garante que isso ocorra, pois o modo como se dá a administração pública, presa a uma cúpula central, que dita as normas e detém o capital necessário à implementação das ações, faz com que, mesmo que existam pessoas preparadas e estrutura adequada, muitas vezes se deixe de prestar um bom serviço.

Defende-se a ideia de que as organizações são constituídas por muito mais que uma estrutura física e seu mobiliário, sendo as pessoas fonte de vida, criando, transformando e finalizando os processos, ou seja, representam a massa de trabalhadores à sua disposição.

Como se vê, o clima não representa nada mais que um retrato da cultura organizacional delimitado no tempo, espaço e por fatores econômicos, sociais e pessoais que "por ser subjetivo [...] não representa as regularidades simbólicas da coletividade, indica apenas uma "pulsação" da cultura organizacional, um flash de sua conjuntura" (Srour, 2005, p. 213), podendo ser um indício da necessidade ou não de mudança e, quando está implantada, possibilita verificar se foi positiva ou não para a organização.

Desse modo, a formação da identidade organizacional obedece a processos que, apesar de não se excluírem são contraditórios, pois "parte da cultura organizacional constituise por assimilação da cultura externa e outra parte por contradição de valores externos com defesas contra competições ou agressões”. (MOTTA, 1999, p. 106)

Portanto, existe uma correlação entre a cultura organizacional e a identidade organizacional diante da mudança, visto que aquela possibilita "a criação de um senso de identidade e comprometimento do grupo no alcance dos objetivos comuns, garantindo a estabilidade do sistema social”. (SOUZA, 2014, p.35); por isso, Luppi (1995, p.18) afirmou que "a identidade pode ser transformada, mas não radicalmente mudada".

\section{METODOLOGIA}

A pesquisa apresentou-se como exploratória por "proporcionar visão geral, de tipo aproximativo, acerca de determinado fato" (GIL, 2008, p.27) e descritiva, cujo "objetivo primordial é a descrição das características de determinada população ou fenômeno ou o estabelecimento de relações entre variáveis”. (GIL, 2008, p.28)

Tratou-se de uma pesquisa qualitativa que se utilizou do método de estudo de caso, que destina-se a analisar situações reais no próprio espaço em que ocorrem e explicar variáveis causais do fenômeno em situações complexas. (GIL, 2008, p. 58)

Para a coleta de dados, utilizou-se de dois instrumentos: entrevistas com os

principais gestores do Campus, os anteriores, a mudança para IFPB e os atuais, sendo 
escolhidos os cargos de Diretor Geral, o Diretor de Administração e Planejamento e o Diretor de Ensino, sendo ao todo seis pessoas, três da antiga e três da nova gestão com objetivo de captar por meio de suas falas, características que pudessem representar a cultura organizacional em ambos os momentos vividos pela Instituição; o questionário foi utilizado, desta feita para a escolha dos respondentes fez-se um corte no tempo, sendo escolhido o período de 2008 a 2015 e servidores com mais de 10 (dez) anos de serviço na Instituição, levando-se em conta que estes conheceram a Instituição na época de Escola Agrotécnica Federal e passaram por todo o processo de mudança para Instituto Federal, possibilitando um retrato mais seguro e fiel dessa transição.

Assim, o universo da pesquisa foi formado pelo Campus Sousa do IFPB, o qual possui, atualmente, em seu quadro funcional, 205 (duzentos e cinco) servidores, sendo 104 (cento e quatro) docentes e 101 (cento e um) técnicos administrativos. ${ }^{5}$

\section{ANÁLISE DAS ENTREVISTAS}

Inicialmente, para traçar um parâmetro histórico da organização de acordo com a visão dos gestores, foi solicitado destes que dessem sua visão sobre o momento de mudança vivido pela organização, o que perpassa pelos sentimentos e pela historicidade do momento em si.

Quadro 1 - Percepção dos respondentes sobre o momento da mudança para IFPB

\begin{tabular}{|c|c|}
\hline Entrevistados & $\begin{array}{l}\text { Questão } 1 \text { - A Lei no } 11.892 / 2008 \text { trouxe a mudança da estrutura } \\
\text { organizacional de Escolhas Agrotécnicas Federais (EAFS) para } \\
\text { IFPB, Campus Sousa. Em relação a isso, como você descreveria } \\
\text { o momento dessa mudança? } \\
\text { Respostas }\end{array}$ \\
\hline GESTOR 1-A & $\begin{array}{l}\text { O momento foi impactante [...] todos os diretores das escolas } \\
\text { Agrotécnicas Federais do Brasil que faziam parte da Rede } \\
\text { Federal de Educação Profissional e Tecnológica foi } \\
\text { surpreendido com a nova proposta, até porque as Escolas } \\
\text { Agrotécnicas eram autarquias federais desde o ano de } 1993 \text { e } \\
\text { todas estavam passando por um processo de intenso trabalho } \\
\text { para se tornarem Centros Federais de Educação Tecnológica [...] }\end{array}$ \\
\hline
\end{tabular}

5 Dados extraídos do Sistema Unificado de Pessoal - SUAP. 


\begin{tabular}{|c|c|}
\hline & $\begin{array}{l}\text { a estrutura organizacional dos Institutos era um pouco diferente, } \\
\text { tanto os CEFETs como as Escolas Agrotécnicas passaram a ser } \\
\text { campi de um Instituto em cada estado que possuía uma reitoria a } \\
\text { parte fora das instituições que se juntaram para formar os } \\
\text { Institutos. }\end{array}$ \\
\hline GESTOR 2-A & $\begin{array}{l}\text { Na época foi muito difícil, houve muita resistência porque nós } \\
\text { tínhamos autonomia própria, [...] foi um impacto muito grande } \\
\text { nisso. A resistência foi muito grande. Muitos não queriam } \\
\text { aceitar, mas, infelizmente legislação agente cumpre, e aí ficamos } \\
\text { dependentes do antigo CEFET, que foi transformado na reitoria } \\
\text { do IFPB. }\end{array}$ \\
\hline GESTOR 3-A & $\begin{array}{l}\text { Tensão, incerteza, sensação de perda de autonomia, dúvida em } \\
\text { aceitar ou não, porém sabíamos que não aderindo à junção os } \\
\text { prejuízos seriam maiores. }\end{array}$ \\
\hline GESTOR 1-P & $\begin{array}{l}\text { [...] Nós chegamos no momento em que estava praticamente } \\
\text { definida essa transformação, essa mudança e [...] sendo a central } \\
\text { em João Pessoa, uma unidade descentralizada em Cajazeiras e } \\
\text { outra em Campina Grande. [...] a Escola Agrotécnica formou o } \\
\text { quarto pilar, digamos assim, na construção do IFPB, mas houve } \\
\text { uma discussão, eu acredito pela história que houve até um } \\
\text { momento de decisão dos componentes que faziam parte da EAFs } \\
\text { para dizer se aceitavam, ou qual o melhor caminho. }\end{array}$ \\
\hline GESTOR 2-P & $\begin{array}{l}\text { A mudança tem pontos positivos e negativos, o momento em si } \\
\text { era necessário porque era necessário inserir, por exemplo, o } \\
\text { ensino superior que as Escolas Agrotécnicas, dada à estrutura } \\
\text { não permitiria, [...] inclusive a escola Agrotécnica na época ele } \\
\text { tinha sido aprovado um processo de cefetização que logo em } \\
\text { seguida veio a questão dos IFs. }\end{array}$ \\
\hline GESTOR 3-P & $\begin{array}{l}\text { [...] foi uma mudança gigantesca. [...] Estávamos numa realidade } \\
\text { que era basicamente da educação profissional e do ensino médio. } \\
{[\ldots . .] \text { Não houve essa preparação, foi algo que veio, que }} \\
\text { modificou completamente a estrutura. Porque agora, não havia } \\
\text { mais CEFETS, não havia mais Escolas Agrotécnicas, todas }\end{array}$ \\
\hline
\end{tabular}




\begin{tabular}{|l|l|}
\hline & $\begin{array}{l}\text { agora pertenciam ao ente chamado Instituto Federal [...] a grande } \\
\text { característica dessa transição foi ter que se adaptar a uma } \\
\text { realidade completamente diferente [...] }\end{array}$ \\
\hline
\end{tabular}

Fonte: Dados da pesquisa, 2016.

Pelos relatos do Quadro 1, é possível verificar que a mudança não representou um momento de calmaria, mas de dúvidas, incertezas, sensação de perda, momento de resistência em prol de uma cultura existente, já conhecida e aceita, em contraposição à mudança da organização em aspectos que até então não estavam bem definidos e explicados, segundo os entrevistados.

Percebe-se, ainda, uma maior dificuldade em relação aos gestores no momento da mudança, especialmente o que estava no cargo de maior poder, o Diretor Geral, participou ativamente das discussões, tendo oportunidade junto com outros diretores, de dar sugestões ao MEC que em sua grande maioria não foi acatada, além de servir de elo entre o órgão de demanda e a sua organização, na constante transmissão das informações pertinentes ao momento de mudança.

Por outro lado, na fala dos gestores posteriores à mudança, percebe-se que apesar de terem noção da grande dimensão da mudança, sua atitude é de conformação com a realidade, visto que assumiram o Campus numa fase de maior adaptação e mais aclaramento do que é ser IFPB.

Após a Lei 11.892/2008, a estrutura organizacional do IFPB Campus Sousa passou por um processo de expansão com o intuito de se adequar ao organograma do Instituto Federal da Paraíba e às necessidades geradas pela criação de novos cursos nas várias modalidades de Ensino.

Assim, antes da mudança, existiam além da Direção Geral, apenas os Departamentos de Administração e Planejamento e Departamento de Desenvolvimento de Ensino com suas respectivas Coordenações e Seções.

Atualmente, os Departamentos foram transformados em Diretorias, obtendo maior abrangência e, dentro destas, se tem os Departamentos que foram acrescentados, passando de três para nove, como também as Coordenações; porém, é preciso dizer que para cada Diretoria, Departamento e Coordenação, deveria se ter uma função gratificada correspondente ao grau de responsabilidade, o que foi prometido aos gestores no momento de construção da 
proposta de Ifetização ${ }^{6}$, porém até o momento não foi alcançado em sua plenitude, como afirma o entrevistado Gestor 3-P:

Foram ampliados cargos, mas, foram criados mais cargos em nível de reitoria. [...] Que haveria uma estrutura maior, mas isso não se confirmou, nós tivemos uma ampliação para uma estrutura mais parecida com uma universidade, mas, basicamente, com a mesma estrutura que havia antes.

Com essa ampliação de funções, percebe-se uma maior especificidade na área de atuação, dando ênfase em atividades que antes não recebiam um tratamento mais específico, apesar de certa relevância como a pesquisa e extensão, principalmente, porque estas seriam mais vinculadas à educação superior, pensamento que vem sendo modificado há alguns anos.

No que se refere ao grau de instalação da mudança no Campus, é perceptível que muito já se avançou, se podendo dizer que a adaptação foi quase total, a não ser por certa resistência de parte, principalmente, dos servidores mais antigos no que tange a algumas características culturais adquiridas após a Ifetização que eles acham que trouxeram uma perda no sentido da convivência entre os servidores, dos valores e rituais existentes anteriormente e que eles consideram muito importantes para a convivência enquanto organização.

Assim, quando indagada se os valores, crenças, rituais e cerimônias existentes antes da mudança permanecem ou se já se perdeu, a gestora respondeu:

\begin{abstract}
Nessa parte aí, houve muita mudança, nessas crenças. Porque hoje [...] nós temos mais de 200 (duzentos) servidores, o que só perde para João Pessoa. Quer dizer, são pessoas que não são daqui, transitórias, vão e vêm e não tem mais aquela coisa familiar como tinha a Escola Agrotécnica. Isso realmente fez falta, porque nós éramos uma família, uma família muito bem unida e aí houve aquela dispersão. (GESTOR 2-A)
\end{abstract}

Os demais entrevistados apontaram algumas razões para a mudança dos valores, crenças, rituais e cerimônias, tais como: o aumento do número de servidores e o fato de a grande maioria residir fora do município de Sousa, a divergência na percepção da organização como ambiente de trabalho coletivo, o crescimento de individualismo como modo de vida, ou seja, deixou-se de pensar na organização como um coletivo no qual todos têm que ter sua parcela de contribuição, preocupação esta demonstrada na fala de todos os entrevistados.

No que se refere à perda da autonomia, esta se deu em todos os aspectos, tendo em vista que, atualmente, o Campus Sousa está diretamente vinculado ao controle sistêmico e de apoio administrativo, patrimonial, financeiro, didático-pedagógico e disciplinar da reitoria representada por todas as suas pró-reitorias.

\footnotetext{
${ }^{6}$ Processo de transformação em Instituto Federal. (Dados da pesquisa, 2016)

Revista Labor Fortaleza/CE, jan/jul 2017 Vol. 01, nº 18, p. 31-49 ISSN 1983-5000
} 
Em decorrência da falta de autonomia, quando da transformação em Campus do IFPB, a dependência que antes era apenas em relação a um órgão externo representado pelo MEC, agora passou a ser sentida dentro da própria estrutura, representada pela reitoria e sua base administrativa, o que poderia parecer de fácil resolução vista de fora, mas que se mostra complexa, tendo em vista que aquela tem em suas mãos a responsabilidade de administrar, hoje, mais de 21 Campi na Paraíba, todos com suas necessidades e peculiaridades.

Destaque-se a fala de um dos gestores:

Ainda, vai demorar um pouco porque, como a gente até já conversou antes. Tem uma frase até da filosofia oriental, que diz que, "o maior adversário que agente enfrenta somos nós mesmos", uma frase do budismo [...] não é o simples fato transformar uma coisa em outra que ela vai deixar de pensar da forma como pensava anteriormente [...] não podemos perder de vista que há mudanças, mas não podemos também deixar tudo de bom que aconteceu (GESTOR 3 - P)

De um modo geral foi possível se inferir que as mudanças no Campus Sousa ainda não foram incorporadas totalmente, pois a maioria dos gestores acredita haver resistências, de modo que, a organização ainda vai demorar a se adequar às novidades trazidas pelo IFPB e, consequentemente, chegar a um período de estabilidade cultural. Alguns atribuem a resistência existente ao desconhecimento da Lei e a falta de uma socialização mais efetiva. Por outro lado, os entrevistados acreditam que a resistência se apresenta em maior grau entre os servidores antigos que vivenciaram a estabilidade da cultura EAFS, o que os fazem ficar um pouco avessos à mudança daquilo que representava seu mundo social.

Nesse contexto apresentamos a fala do Gestor 3-P, que retrata bem o momento vivido pelo Campus Sousa: “[...] nós sabíamos exatamente o que era uma Escola Agrotécnica Federal [...] hoje se você perguntar, por exemplo, o que é o Instituto Federal, um colega vai dizer uma coisa, outro pode dizer outra diametralmente oposta [...]".

Alguns dos gestores lembram que para mudar a identidade, se requer tempo, de modo que a identidade como EAFS ainda está bem presente, principalmente, para os servidores mais antigos que se sentem meio perdidos em meio a essa mudança, conforme a fala do Gestor 1-P:

[...] uma identidade se constrói com o tempo porque não é simplesmente eu dizer eu tenho uma identidade com determinado setor [...] os servidores, que aqui estavam, enquanto Escola Agrotécnica tinham uma identidade com a Escola Agrotécnica [...] isso foi construído ao longo do tempo e de repente chega e diz olhe Escola Agrotécnica não existe mais, agora é IFPB [...] você passa a se sentir meio órfão, eu era Agrotécnica, eu sou IFPB e agora?

Portanto, as falas levam a inferir que a identidade IFPB Campus Sousa existe apenas no sentido formal, já que na realidade, tendo sido imposta de certa forma pela Lei de Revista Labor Fortaleza/CE, jan/jul 2017 Vol.01, nº 18, p. 31-49 ISSN 1983-5000 
criação dos Institutos, não houve tempo ainda para uma construção e incorporação no pensamento e no fazer dos servidores como um todo, de forma a lhes dar segurança na definição da organização em que trabalham.

\section{ANÁLISE DOS DADOS DO QUESTIONÁRIO}

O Gráfico 1, mostra que, entre os respondentes o gênero masculino foi predominante com $51,2 \%$, enquanto do gênero feminino ficou com $48,8 \%$, no entanto, por ser o percentual de diferença menos de $3 \%$, existe (...).

Gráfico 1 - Distribuição da amostra quanto ao gênero

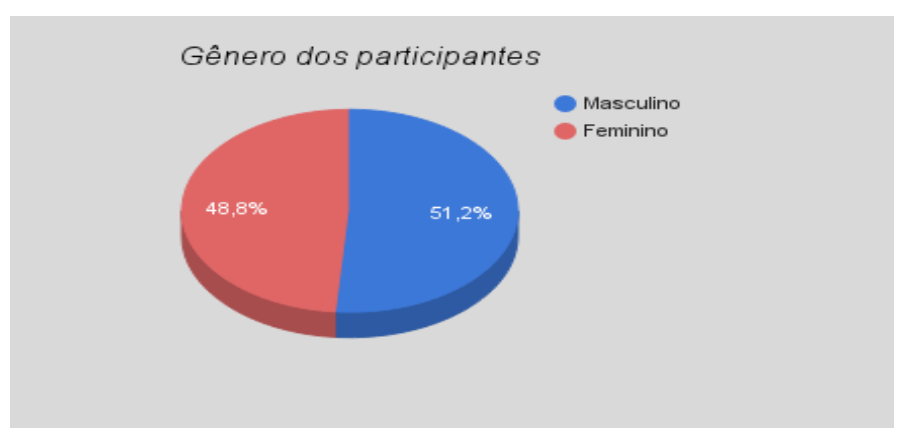

Fonte: Dados da pesquisa, 2006.

No que se refere à idade dos respondentes apresentada no Gráfico 2, percebe-se que a grande maioria deles, ou seja, $78 \%$ estão com mais de quarenta e cinco anos, seguidos dos que ficam na faixa etária de 41 a 45 anos com 14,6\%; a faixa entre 35 a 40 anos ficou com $4,87 \%$ e a faixa de 31 a 35 anos $2,43 \%$, percebendo-se que nenhum dos respondentes está na faixa de 25 a 30 anos. Assim, entende-se que o grupo de servidores está numa faixa etária caracterizada por uma idade laboral intensa, pois a maior parte das pessoas nessa faixa de idade já terminou o seu ciclo de educação formal, o que possibilita uma maior dedicação às atividades de seu cargo, porém merecem atenção em relação a capacitação e atualização para novos conhecimentos.

Gráfico 2 - Distribuição dos respondentes quanto à Idade

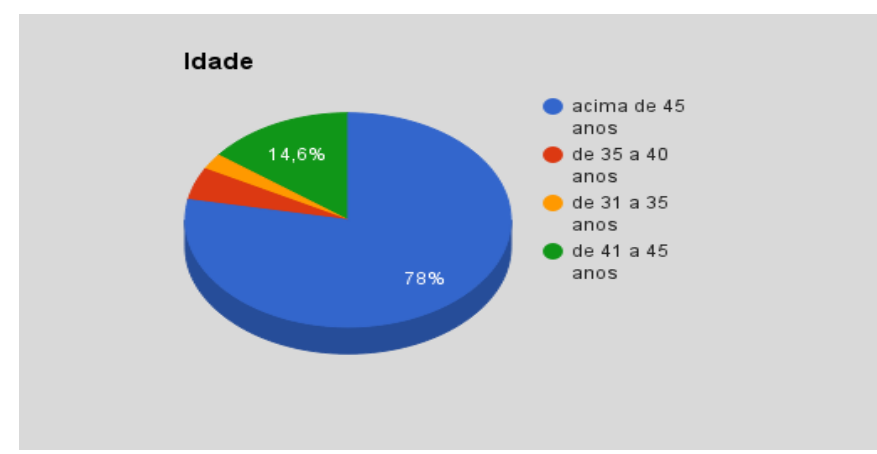


Por outro lado, o Gráfico 3 leva a constatação que os respondentes possuem um ótimo nível de educação formal, sendo que 31,7\% possuem especialização, 26,8\% têm o grau de mestre e 19,5\% de Doutor; além disso, é importante notar que menos de $8 \%$ estão entre o fundamental incompleto e o nível médio incompleto e que devido a idade deste pode-se inferir que os que se encontram nesse nível de educação acharam mais dificuldades para complementá-la.

Gráfico 3- Distribuição da amostra quanto a educação formal

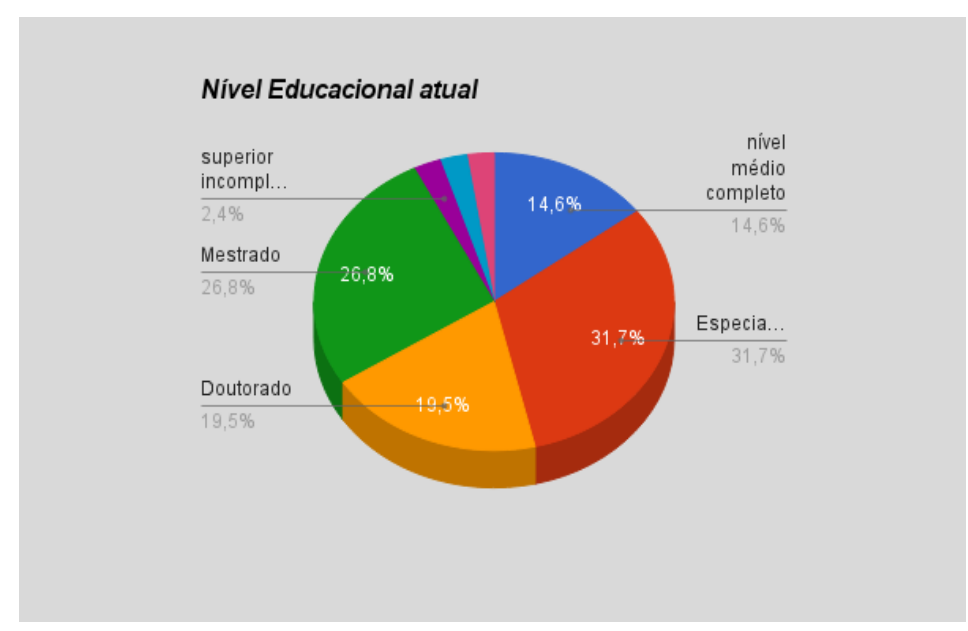

Fonte: Dados da pesquisa (2016)

Concluindo o perfil dos respondentes, o Gráfico 4, traz a distribuiçãa destes em relação ao tempo de serviço na organização, sendo que em sua expressiva maioria, ou seja, $58,5 \%$ deles, possuem mais de 21 anos de serviço, de modo que para estes, a cultura organizacional da EAFS por estar arraigada por anos, o que representa para alguns toda uma vida profissional que ainda está bem presente.

Gráfico 4- Distribuição da amostra quanto ao tempo de serviço na organização

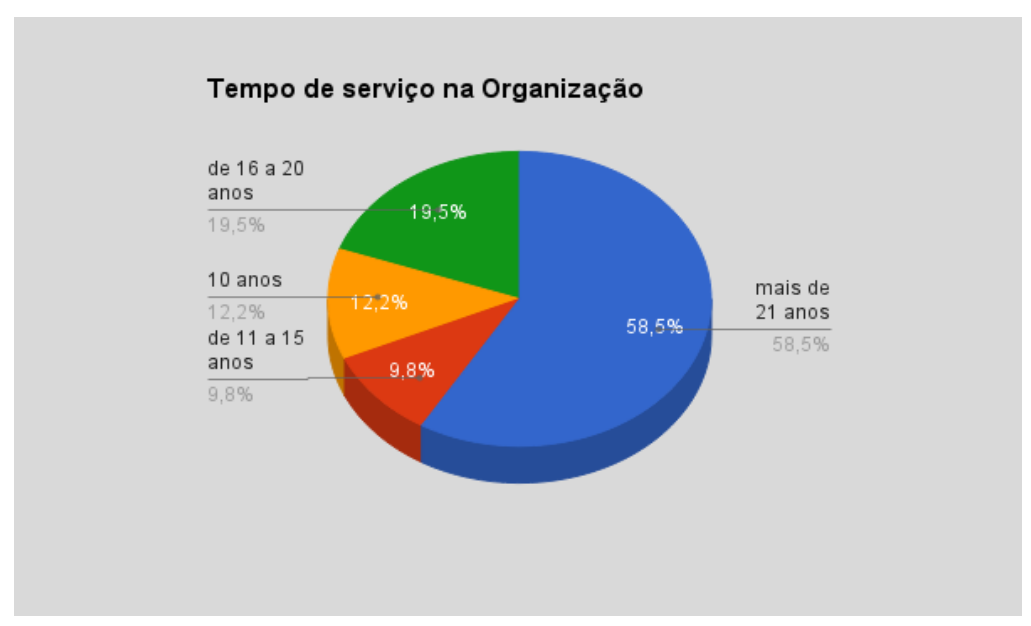

Fonte: Dados da pesquisa, 2006. 
Assim, para os servidores respondentes, a mudança incorporada pela Lei de criação dos Institutos trouxe a necessidade de um processo de assimilação dos novos valores e do novo perfil da organização o que não é fácil, mas é urgente que seja realizado sob pena de estacionamento de sua atividade funcional. É interessante notar que os servidores que possuem menos de 15 anos de serviço representam apenas $22 \%$ da amostra.

Os itens avaliados referentes à mudança organizacional, no Gráfico 5, trazem como resultados que a maioria dos respondentes, ou seja, 39,0\% concordam levemente com a afirmativa de que tiveram acesso às informações sobre a mudança. Passando para $70,7 \%$ dos que concordam levemente que as informações recebidas foram suficientes para a compreensão do novo modelo de gestão, demonstrando um nível alto de concordância em relação ao acesso e entendimento das informações. Um fator interessante e que merece ser relatado ainda nesse item é que a porcentagem de servidores que não possuem uma opinião definida foi a mais alta de todo o grupo de respostas, ou seja, 15,0\%.

Gráfico 5 - Distribuição de valores sobre a mudança organizacional

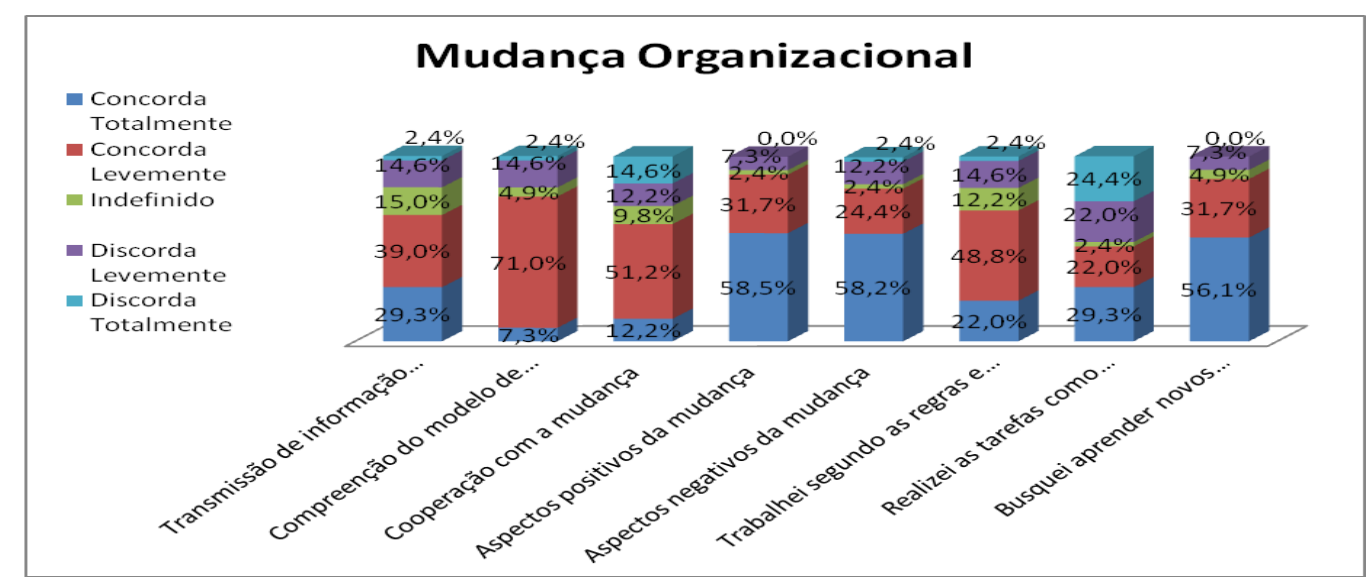

Fonte: Dados da pesquisa, 2006.

Em relação à cooperação com a mudança, os respondentes que concordam levemente e foram maioria tiveram percentual de $51,2 \%$, sendo considerada uma alta taxa de concordância.

Já no que se refere a pontos positivos e negativos da mudança, 58,5\% concordam totalmente que foi positiva a expansão da estrutura física e a chegada de novos servidores no Campus Sousa, enquanto que 58,2\% concordam totalmente que foi negativa a perda da autonomia e a dependência em relação à Reitoria, de modo que foi considerada muito alta a taxa de concordância. 
Por outro lado, do total de respondentes, existem 29,3\% que concordam totalmente com a afirmativa de que continuaram fazendo as tarefas como sempre fizeram, demonstrando descompromisso com o processo de mudança; ao contrário, 24,4\% discordam totalmente com essa afirmativa, podendo-se inferir que houve uma mudança para este percentual de pessoas no modo de fazer as coisas. Isto é confirmado pelo percentual de pessoas que concordaram totalmente com a afirmativa de que buscaram aprender novos métodos de trabalho e especialização para contribuir com o sucesso da gestão, sendo um percentual de concordância muito alto de 56,1\%; além de $31,7 \%$ que concordam levemente, inferindo-se assim, que há no Campus uma abertura bastante significativa dos servidores para o novo, pela melhoria da Organização e para a aprendizagem contínua.

Gráfico 6 - Distribuição de valores sobre a Cultura Organizacional

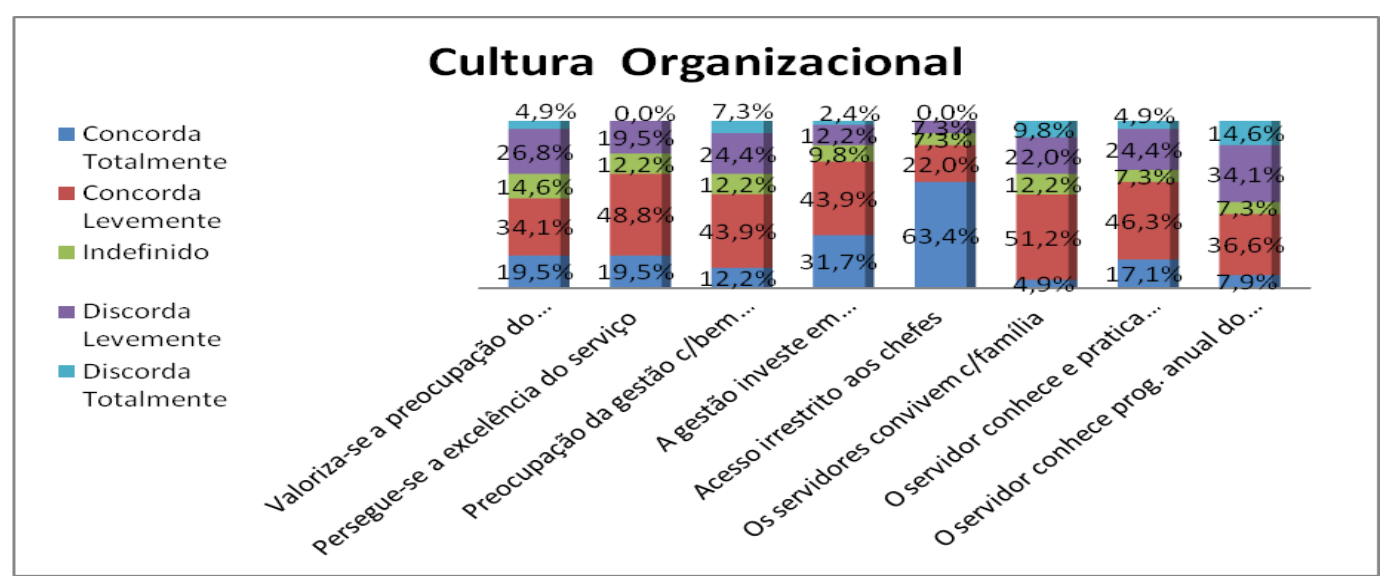

Fonte: Dados da pesquisa, 2006.

Analisando o Gráfico 6, constata-se que 34,1\% concordam levemente com a existência de valorização da preocupação do servidor com a qualidade do serviço, seguido de $26,8 \%$ que discordam levemente com isto.

Quanto à variável seguinte sobre a excelência do serviço, a taxa de concordância foi de 48,8\% para concordo levemente e de 19,5 para concordo totalmente. Ao mesmo tempo, os que discordavam levemente com a afirmativa somaram 19,5\%. Nos itens até aqui avaliados, tratou-se da qualidade de formas diferentes, uma como fator interno de valorização do servidor e a outra a qualidade, tendo em vista a satisfação do público externo (comunidade, alunos e pais), demonstrando que a preocupação dos respondentes está mais voltada para a oferta de um serviço de qualidade.

No que tange ao bem-estar do servidor, os respondentes responderam positivamente as afirmativas que obtiveram um nível de concordância alto (CL) de 43,9\%, inferindo-se que a gestão se preocupa com o bem-estar dos servidores e investe na sua Revista Labor Fortaleza/CE, jan/jul 2017 Vol.01, nº 18, p. 31-49 ISSN 1983-5000 
qualificação e capacitação, afirmativa possível de ser constatada pelo número de servidores que estão, atualmente, em especializações, Mestrados e Doutorados, bem como participando de capacitações relacionadas às suas atividades. Ainda quanto a essas afirmativas, é preciso que se diga que foi encontrado um percentual alto (DL) de discordância de 24,4\%, levando-se a entender que estes servidores ainda não se sentem abarcados pelas políticas de qualificação e capacitação de pessoal do Campus Sousa.

Quanto aos relacionamentos internos entre os servidores e entre estes e seus chefes, encontrou-se o maior percentual de concordância de todo o grupo de dados analisados, sendo o nível de concordância considerado muito alto (CT) de 63,4\%, o que pode ser considerado um ponto positivo, pois o fato de a gestão se manter próxima aos servidores é imprescindível no momento de mudança vivido pelo Campus, tendo em vista que o papel da liderança é mostrar o caminho a ser seguido.

Quanto ao conhecimento da organização, a primeira afirmativa que tratou dos valores culturais e a sua prática recebeu um percentual alto de concordância (CL) de 46,3\% e $17,1 \%$ concordam totalmente (CT). Ao mesmo tempo, um percentual considerável de $24,4 \%$ (DL) discorda da afirmativa, podendo-se entender que, devido ao processo de mudança em curso, a utilidade prática desses elementos não esteja ainda bem definida na mente dos servidores.

$\mathrm{Na}$ última afirmativa do Gráfico 6 que diz respeito ao conhecimento da programação anual de trabalho do Campus e suas prioridades, é possível visualizar uma aproximação maior entre o nível de concordância (CL) 36,6\% e o de discordância (DL) de 34,1, além disso, nesse item, houve a maior taxa de pessoas indefinidas quanto a resposta, somando $14,6 \%$. Isso revela que uma parte significativa da organização está ficando de fora do conhecimento das informações pertinentes ao seu trabalho, merecendo maior atenção por parte da gestão.

$\mathrm{Na}$ análise do Clima Organizacional foram selecionadas 12 (doze) afirmativas, sendo oito com sentido positivo e quatro com sentido negativo, que tinham a intenção de verificar o nível de satisfação dos servidores com a organização, de modo a demonstrar se existe um clima favorável, ou não, decorrente do processo de mudança organizacional. 
Gráfico 7 - Distribuição de valores relacionados ao Clima Organizacional

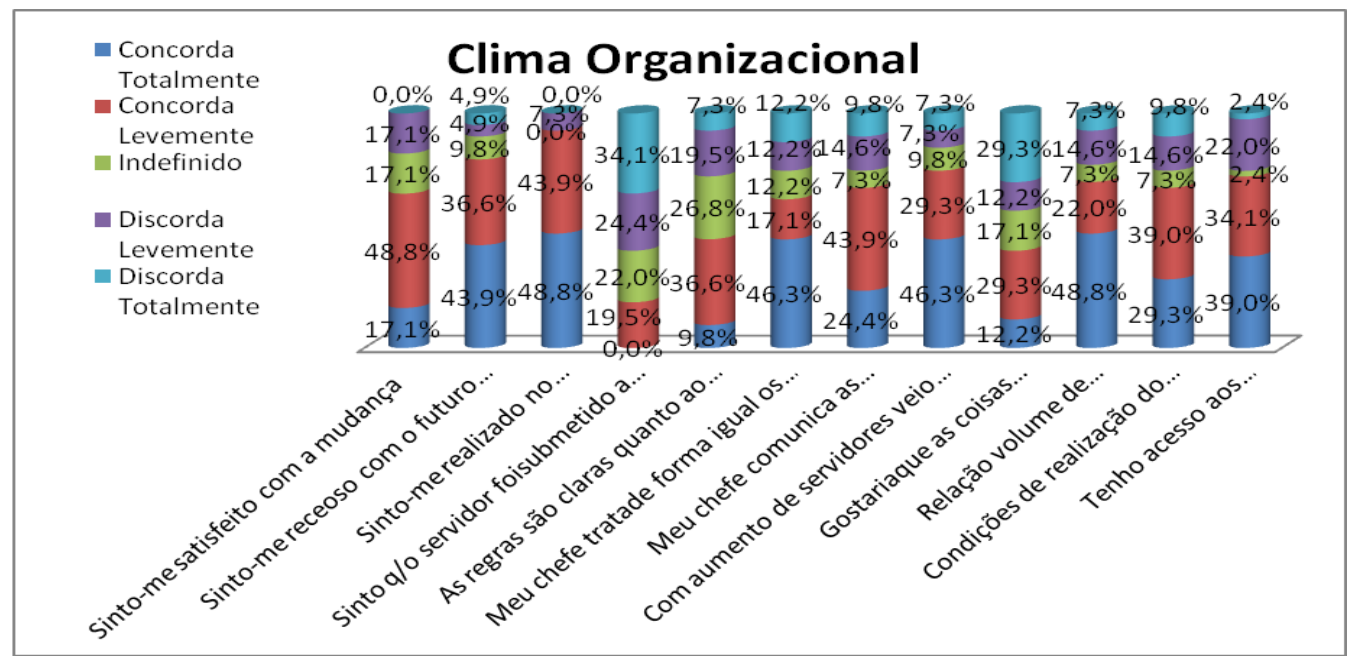

Fonte: Dados da pesquisa, 2006.

No Gráfico 7, a primeira afirmativa tratou de avaliar o grau de satisfação dos servidores com a mudança verificada na organização, constatando-se um alto grau de satisfação (CL) de 48,8\%, e os servidores que concordaram totalmente (CT) totalizaram um percentual de $17,1 \%$, podendo-se inferir que a mudança foi positiva.

Quanto à satisfação com a organização, a maioria de afirmativas tinha sentido negativo. Assim, com relação ao sentimento de receio em relação ao futuro do Campus e do Instituto, 43,9\% concordaram totalmente (CT), e 36,6\% concordaram levemente (CL), demonstrando um nível muito alto de insegurança dos servidores quanto ao futuro da organização, o que pode ser decorrente da identidade ainda indefinida, como também do momento político e das dificuldades financeiras vividas pelas organizações públicas, especialmente, as educacionais.

Quanto à satisfação em relação aos chefes e ao tratamento dispensado aos subordinados, a satisfação foi muito alta (CT) de 46,3\% e alta (CL) obtendo percentual de $17,1 \%$, ou seja, os servidores entenderam que o tratamento é igualitário. Já no que tange à comunicação da mudança no fluxo dos processos e procedimentos do trabalho foi considerada satisfatória, obtendo os percentuais de concordância de 43,9\% (CL) e 24,4\% (CT).

Uma questão importantíssima para o Clima Organizacional diz respeito à convivência no ambiente de trabalho, assim quando questionados se o aumento de servidores trouxe dificuldades de convivência e distanciamento em relação à Cultura Organizacional $46,3 \%$ concordaram totalmente (CT), enquanto que, 29,3\% de servidores concordaram levemente (CL) com a afirmativa, levando a percepção que os servidores sentem a 
arrefecimento da cultura EAFS, principalmente, pela entrada de novas pessoas com entendimentos e interesses diferentes e sem um espírito de coletividade existente antes.

Assim, para os respondentes o nível de realização com o cargo e função é considerado muito alto, pois 48,8\% concordam totalmente (CT), acompanhados de 43,9\% que concordaram levemente (CL), o que leva a crer que estes servidores estão nos cargos que desejavam e realizam as atividades compatíveis com suas expectativas.

Por fim, as condições de realização do trabalho foram consideradas positivas, pois $29,3 \%$ dos respondentes concordaram totalmente (CT) com a afirmativa e 39,0\% concordaram levemente (CL). Já quanto ao acesso aos instrumentos necessários ao trabalho, o percentual de satisfação ficou em 39,0\% que concordaram totalmente (CT) e 34,1\% que concordaram levemente (CL), sendo assim, a organização está atendendo satisfatoriamente no que diz respeito ao ambiente e aos instrumentos necessários para a realização do trabalho.

\section{CONSIDERAÇÕES FINAIS}

Quanto à cultura organizacional do IFPB, Campus Sousa, constatou-se que a organização está entrando numa fase de maior tranquilidade, pois os servidores respondentes conhecem e, de certa forma, se identificam com o novo modelo de gestão e seus valores. No entanto, há ainda a necessidade de uma socialização constante para que os valores, crenças, rituais, bem como a missão, visão, objetivos e modelo de gestão passem a ser incorporados na prática diária dos servidores, e que estes se identifiquem verdadeiramente com a nova instituição que foi formada.

Quanto ao clima, percebe-se que, apesar de alguns problemas gerados pelo aumento da quantidade de cursos, pela chegada de novos servidores e a remoção constante destes, alterando o clima de familiaridade, característica da EAFS, existe, hoje, uma ótima aceitação da mudança, além de satisfação com as normas e organização do trabalho e com o fato de os chefes serem abertos ao diálogo.

Em geral, o que se observou nas entrevistas é que tanto os servidores que ocuparam cargos de chefia na época da mudança como os que estão atualmente nestes cargos acreditam que a mudança foi benéfica pelo crescimento que proporcionou ao Campus, pelo aumento dos cursos e da quantidade de servidores, pela visibilidade que ela deu à Instituição, e estão satisfeitos e confiantes no sucesso da proposta.

No que tange à formação da identidade, verifica-se que os servidores mais antigos, pelo fato de terem conhecido e compartilhado a cultura anterior, têm maior 
dificuldade de assimilar a mudança nos valores e crenças organizacionais e veem a necessidade de a gestão promover a socialização para a assimilação dos valores, crenças e rituais da Organização, pois o desconhecimento das leis e normas Institucionais ainda não favorece a incorporação da identidade em sua forma real, existindo apenas de forma abstrata ou formal.

\section{REFERÊNCIAS}

ALEXANDRINO, Marcelo. Direito Administrativo descomplicado. 19 ed. rev. e atual. Rio de Janeiro: Forense; São Paulo: MÉTODO, 2011.

ANDRÉ, Marli Eliza Dalmazo Afonso de. Estudo de caso em pesquisa e avaliação educacional. Brasília: Liber Livro Editora, 3 ed., 2008.

BARDIN, Laurence. Análise de Conteúdo. São Paulo: Edições 70, 2016.

BORGES, Renata Simões Guimarães e; MARQUES, Antonio Luiz. Gestão da mudança: uma alternativa para a avaliação do impacto da mudança organizacional. R. Adm. FACES Journal Belo Horizonte v. 10 n. 1 p. 95-113. Jan/mar 2011. ISSN 1984-6975 (on line). Acesso em: 06 de jun de 2016.

BRASIL. Lei no 11.892, publicada em 29/12/2008. Diário Oficial da República do Brasil. Poder Executivo, Brasília, DF. Disponível em:

<http://www.planalto.gov.br/ccivil_03/_ato2007-2010/2008/lei/111892.htm >. Acesso em: 25 mar. 2016.

BRESSER-PEREIRA, L. C. Da administração pública burocrática à gerencial. Revista do Serviço Público, v. 120, n.1, 1996.

CHAVES, Rossana Costa. Resistência à mudança: um estudo das relações entre moderadores individuais e organizacionais, atitudes e comportamentos de servidores de uma instituição pública em processo de mudança. Originalmente apresentada como dissertação (mestrado), Universidade Federal de Minas Gerais, 2005.

DUTRA, Joel Souza. A utopia da mudança das relações de poder na gestão de recursos humanos in Cultura e poder nas organizações. Org. FLEURY, M. Teresa Leme $2^{\mathrm{a}}$ ed. São Paulo: Atlas, 2015.

FLEURY, Maria Tereza et al. Cultura e poder nas organizações. $2^{\text {a }}$ Ed. São Paulo: Atlas, 2015.

FLICK, Uwe. Qualidade na pesquisa qualitativa. Porto Alegre: Artmed, 2009. 
. Introdução à pesquisa qualitativa. Tradução Joice Elias Costa. 3 Ed. Porto

Alegre: Artmed, 2016.

FRANCO, Maria Laura P. B. Análise de Conteúdo. $4^{\mathrm{a}}$ ed. Brasília: Líber livro editora, 2012. FREITAS, Alexandre Borges de. Traços brasileiros para uma análise organizacional... in Cultura Organizacional e Cultura Brasileira. Org. MOTTA, Fernando C. Prestes. 1. Ed., 6 reimpressão. São Paulo: Atlas, 2006.

GIL, Antonio Carlos. Métodos e técnicas de pesquisa social. 6. Ed. São Paulo: Atlas, 2008. Estudo de caso. São Paulo: Atlas, 2009.

HELDER, Desiree Louise; CASTRO, André Luis de. Satisfação do servidor público no trabalho: um estudo de caso nos Centros de referência de Assistência Social de Paranavaí. (artigo) UNOPAR Cient. Ciênci. Jurid. Empres., Londrina V.16 n.2, p. 192-198, set 2015 (on line). Acesso em: 21 nov. 2016.

INSTITUTO FEDERAL DA PARAÍBA. Plano De Desenvolvimento Institucional Do IFPB PDI 2015-2019. Disponível em:

< http://www.ifpb.edu.br/institucional/pdi/PDI_2015_2019.pdf/view $>$ Acesso em: 18 ago. 2016.

LOPES, Jorge. $\mathbf{O}$ fazer do trabalho científico em ciências sociais aplicadas. Recife: Ed. Universitária da UFPE, 2006.

LÜCK, Heloisa. Gestão da Cultura e do clima Organizacional da escola. 2. ed. Petrópolis, RJ: Vozes, 2015. (Série Cadernos de Gestão).

LUPPI, Galvani. Cultura Organizacional: passos para a mudança. Belo Horizonte: Luzazul Editorial, 1995.

MACEDO, Ivanildo Izaias de; RODRIGUES, Denize Ferreira et. al. Aspectos comportamentais da Gestão de Pessoas. 9. Ed. rev. e atual. Rio de Janeiro: Ed. FGV, 2007. MARCONI, Marina de Andrade; LAKATOS, Eva Maria. Fundamentos de metodologia científica. $6^{\text {a }}$ ed. São Paulo: Atlas, 2007.

MINAYO, Maria Cecília de Souza. O desafio do conhecimento: pesquisa qualitativa em saúde. 14. ed. - São Paulo: Hucitec, 2014.

, Maria Cecília de Souza (org.). Pesquisa social: teoria, método e criatividade. 34. ed. - Petrópolis, RJ: Vozes, 2015. (Coleção temas sociais).

MÓL, Anderson Luiz Resende et al. Clima Organizacional na Administração Pública: um estudo da Secretaria de Estado da Administração e dos Recursos Humanos do Rio Grande do Norte. Rio de Janeiro: Editora FGV, 2010. 
MORGAN, Gareth. Imagens da organização. São Paulo: Atlas, 2010.

MOTTA, Paulo Roberto. Transformação organizacional: a teoria e a prática de inovar. Rio de Janeiro: Qualitymark Ed., 1999.

NEGREIROS, Daniel Pinto. A cultura organizacional identificada através dos valores e práticas organizacionais. Dissertação (Mestrado) - Universidade Potiguar. Natal, 2011, 85f. OLIVER, Marilene. Planejamento estratégico e gestão de recursos humanos: casos e descasos nas universidades federais. In: Encontro da Associação Nacional dos Programas de Pós Graduação em Administração, Anais, Campinas: ENANPAD, 2001.

OLIVEIRA, D. P. R. Planejamento estratégico: conceitos, metodologias e práticas. 19. ed. São Paulo: Atlas, 2003.

PACHECO, Eliezer. Institutos Federais: uma revolução na educação profissional e tecnológica. São Paulo: Editora Moderna, 2011.

PAULA, Ana Paula Paes de. Por uma nova gestão pública: limites e potencialidades da experiência contemporânea. Rio de Janeiro: Editora FGV, 2005.

SANTOS, Jorge Luiz dos. O que é cultura. 10 ed. São Paulo: Brasiliense, 1991.

SCHEIN, Edgar H Marioti. - S. Cultura Organizacional e liderança. Tradução Ailton Bonfim Brandão. Revisão técnica Humberto. São Paulo: Atlas, 2009.

SOUZA, Carla Patrícia da Silva. Cultura e clima organizacional: compreendendo a essência das organizações. Curitiba: Intersaberes, 2014.

SROUR, Robert Henry. Poder, cultura e ética nas organizações: o desafio das formas de gestão. Rio de Janeiro: Elsevier, 2005.

Poder, Cultura e ética nas organizações. $3^{\mathrm{a}}$ ed. Rio de Janeiro: Elsevier, 2012.

SILVA, Reinaldo O. Teorias da administração. São Paulo: Pioneira Thomson Learning, 2008.

TEIXEIRA, Lucia Helena Gonçalves. Cultura Organizacional e projeto de mudança em escolas públicas. Campinas, SP: Autores Associados, São Paulo, SP: UMESP: ANPAE, 2002.

TACHIZAWA, Takeshy. Gestão de instituições de ensino. 4 ed. Ver e ampl. Rio de Janeiro: Editora FGV, 2006.

WEBER, Max. Economia e Sociedade. Vol 2. 1 Ed. Brasília: Editora UNB, 1999.

WOOD JR., Thomaz (Coord). Mudança organizacional: aprofundando temas atuais em administração de empresas. 5 Ed. São Paulo: Atlas, 2009. 328p. 